\title{
Design and technology in the development of potters' lathes for modeling with terracota: the case of Cabo de Santo Agostinho
}

\author{
Silva, G. D.A ${ }^{\text {a }}$, Cordeiro, E. D. ${ }^{\text {a }}$, Silva, A. C.R. ${ }^{\text {a }}$, Andrade, A.Q. ${ }^{\text {a }}$, Cavalcanti, V.P. ${ }^{\text {a }}$ \\ ${ }^{a}$ Laboratory The Imaginary, Department of Design, Universidade Federal de Pernambuco, Recife, PE Brazil.
}

\begin{abstract}
This article reports the experience of the design team of the Laboratory The Imaginary in the process of developing an electric potter's lathe which respects the biomechanics of the body, helps to development the task, maintains the archetype of traditional equipment, and improves the mechanical efficiency of the power transmission system. The design method used was based on the axes of research, analysis, development and monitoring, and focused on the product and with partners: the artisans and engineering and production teams. The main results point to ergonomic improvements in the biomechanical and dimensional aspects, and a decrease in the risk of accidents and occupational diseases. The experience of this case also highlights the gains arising from the relationship between design, engineering and users (artisans) in developing products with a design that can be easily replicated for other communities of potters in the state. This and other actions are part of the outlook of the Laboratory the Imaginary which in partnership with local authorities, wishes to see the craft activities continue and to give value to the culture of the city.
\end{abstract}

Keywords: product design, potter's lathe, ergonomics, craft production

\section{Introduction - The problem}

The Ceramic-Making Community of the Espaço Mauriti, a complex of potteries located in the municipality of Cabo de Santo Agostinho, Pernambuco, has been in existence for more than 40 years and involves about 150 people amongst whom are craftsmen and their assistants in the production of terracotta ceramic utilities. The process of making pieces such as filters, pots and vases, is traditionally modeling on manual (Fig. 1) and/or electric potter's lathes made by the community itself, which, very often, disregards the biomechanical issues of the human body.

Operating on a lathe basically consists placing a lump of clay in the center of a turntable so as to, by means of hand and foot movements, to model the surface of the revolving piece [1]. This activity keeps the position of the torso bent and twisted face on to the lathe and may cause injury to the spine and to muscles of the back [2].

This article reports on the experience of the team from the Laboratory the Imaginary in the process of developing an electric potter's lathe which respects the biomechanics of the body, helps to develop the task, maintains the archetype of traditional equipment, and improves the mechanical efficiency of the power transmission system. 


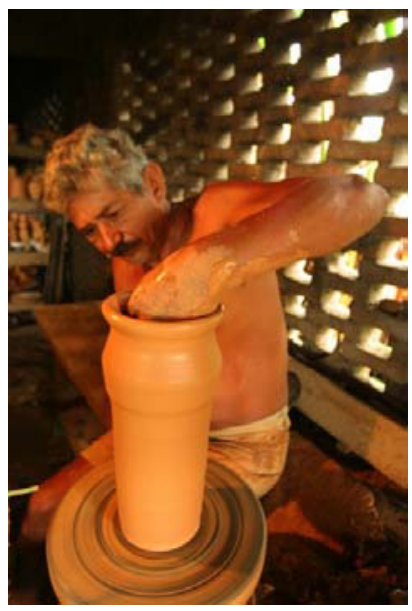

Fig. 01- Artisan modeling a piece on a lathe used by the community.

\section{Design Method: research, analysis, development and monitoring}

The design method used was based on the axes of research, analysis, development and monitoring, used by the laboratory The Imaginary $[3,4,5,6,7]$ for the design of products. The partners in this project were the community's own artisans, students and professors of the mechanical engineering course at UFPE, and technicians from the mechanical workshop, TECRAL Ltda., in technical consultancy and production of the artifacts tested.

The information given here complements the article entitled "Potters' Lathes: ergonomic improvements in equipment that has added value to local culture" [1], presented, in Portuguese, at the $15^{\text {th }}$ Brazilian Congress on Ergonomics in 2008 in which the methodological steps of research, analysis and development carried out to that moment were described. The final considerations of the 2008 article pointed to the need to check the technical feasibility of the product, by making a 1:1 scale prototype and evaluation involving the craftsmen so as to validate its use.

Therefore, the phases described in this article are: the fabrication of functional models in order to dimension the pedals, the range of reach of the operator and adjustments in the power transmission system; tests of use with the artisans, followed by verbalization so as to propose improvements; fabrication of prototypes to check on the usability and technical and financial feasibility of the proposal, namely, producing six lathes set up at the Architect Wilson Campos Junior Center for the Craft Production of Ceramics, located on the edges of the PE-60 highway in Cabo de Santo Agostinho, Pernambuco.

\section{Case Study: the Potter's Lathe}

Having completed the stages of research and analysis [3], some fundamental requirements were generated to guide design alternatives: placing the artisan in an upright stance facing the center of the lathe with the power transmission system of the motor kept some way away from the craftsman's legs; maintaining the archetype of the product traditionally accepted by the community; making it easy for the craftsmen themselves to see to its maintenance. Therefore, the product should promote ergonomic improvement without adversely affecting the issues of production and identification with the craftsmen, namely, maintaining their familiarity with the function and the aesthetics.

Figure 2 is a $3 \mathrm{D}$ representation of the early alternatives of the product developed with the support of AutoCAD, Rhinoceros and 3D Studio Max software.

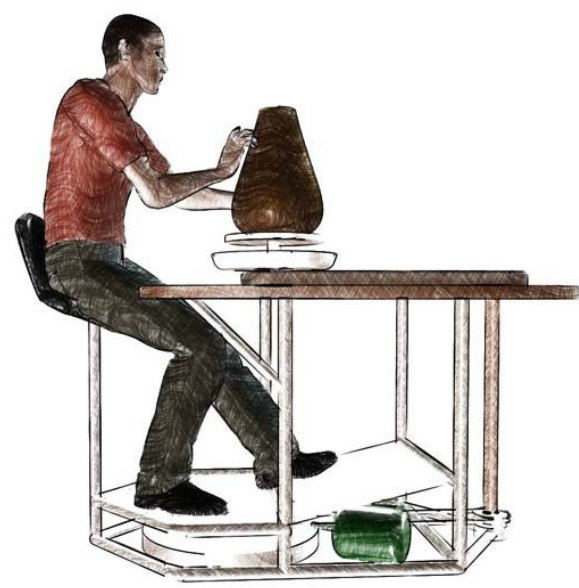




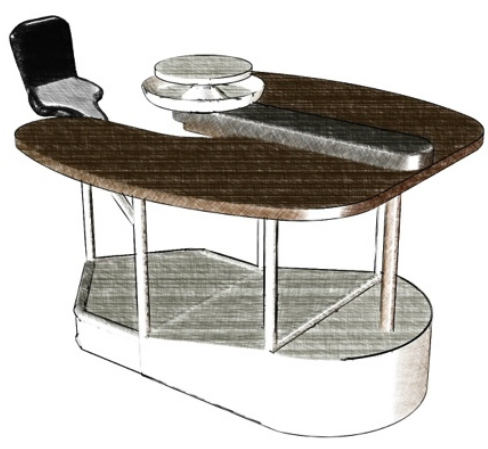

Fig. 2 - Drawing of the alternative design supported by the AutoCad, Rhinos Ceros and 3D Studio Max software

The study of the driving the power transmission system was carried out by students and faculty of the mechanical engineering course at UFPE who initially recommended the use of a $1 / 8 \mathrm{hp}$ motor with a clutch, and of low rpm, the same as that used in industrial sewing machines. Figure 3 presents the model of the transmission system developed with the support of the Solid Works software by Mechanical Engineering students of UFPE.
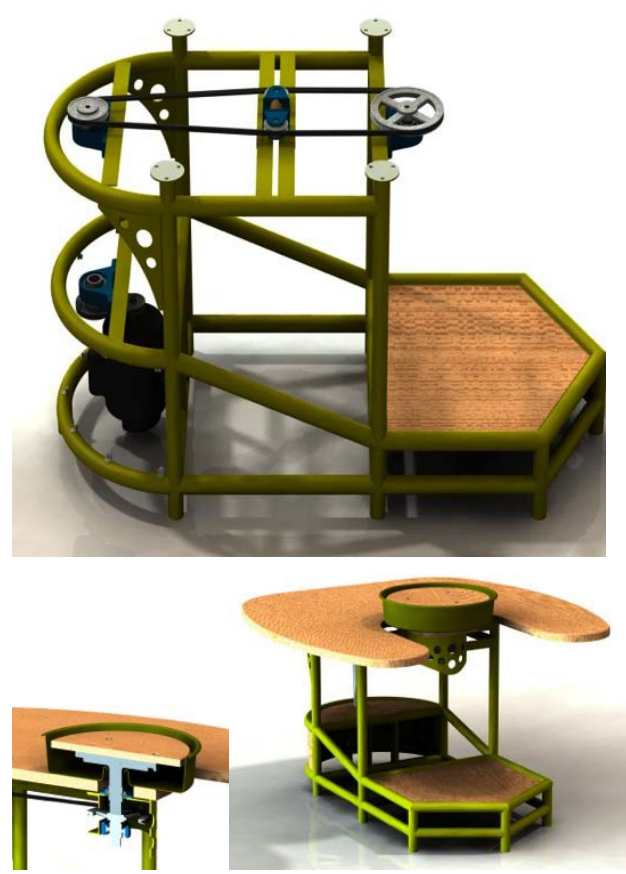

Fig. 3 - Drawing of the transmission system supported by Solid Works.
The first working model was fabricated by TECRAL Ltd. and allowed the positioning of the pedals and the user's range of reach to be evaluated (Fig. 4). In addition to a technical evaluation conducted by the design and engineering teams, the physical model lent itself primarily to evaluating the craftsmen.

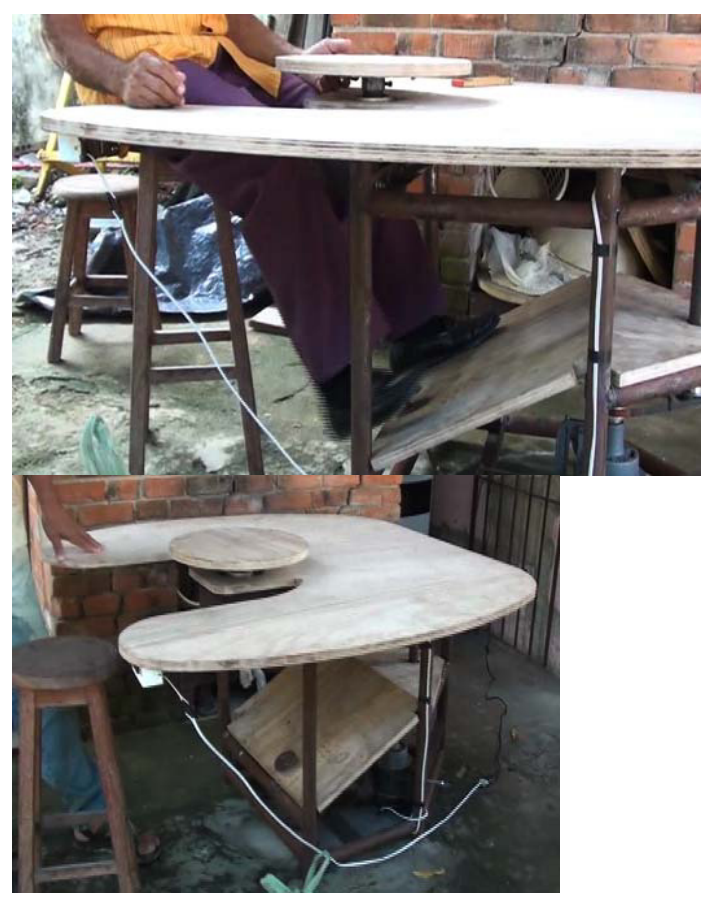

Fig. 4 - First functional model of the lathe developed by the Imaginary

Thus, the craftsmen were invited to test the functional model so as to evaluate the dimensioning of the product and to analyse the performance of the mechanical power transmission system. This step was of fundamental importance to increasing the torque ${ }^{1}$ and reducing the speed of the motor.

\footnotetext{
${ }^{1}$ Torque or moment of force is the tendency of a force to rotate an object about an axis
} 

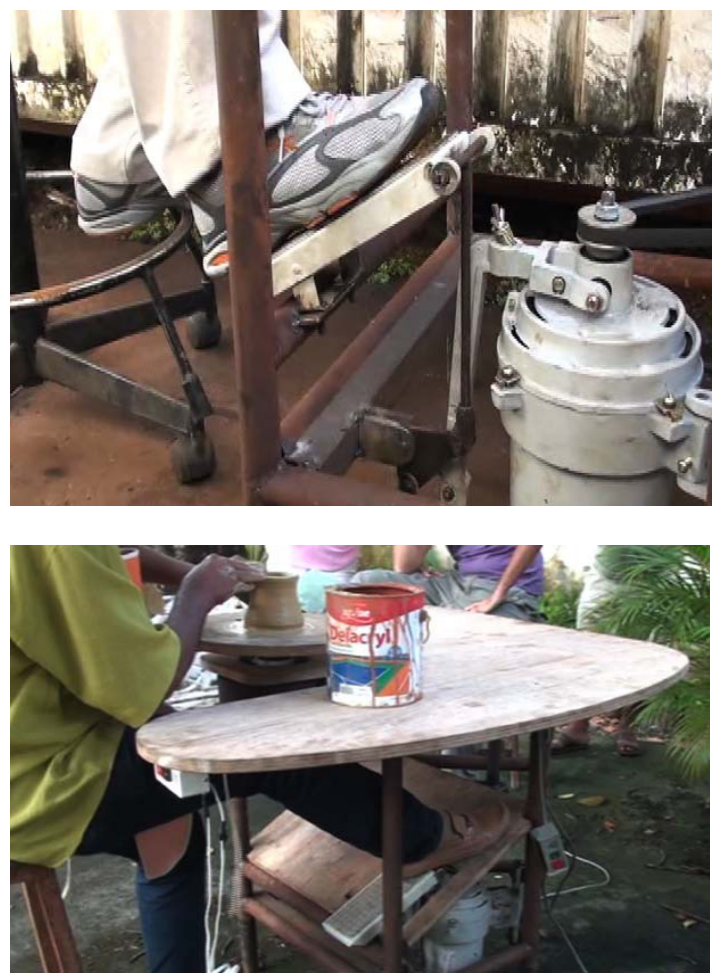

Figs. 5 and 6 - Second functional model of the lathe detailing the drive system

Given the results of the evaluations, the engineering team suggested using a high speed motor with a single phase clutch, of $1 / 3 \mathrm{hp}$. A second working model was made. However, the tests again showed the need to investigate other possibilities so as to maintain identification of the craftsman with the artifact. At this point, a new direction for the project was defined - to use the same mechanical principle as a reference for power transmission and control of the speed of the lathes used by the community.

The new developed system comprises a single vertical axis with no reductions in speed, coupled to a metal disk. This disc is driven by the artisan's foot or a motor, the axis of which is perpendicular to the disk. The modeling of the pieces performed only with the residual movement of the metal disc resulting from its high moment of inertia. Based on this principle, a steel disk was dimensioned with a diameter and mass proportional to the physical structure and the motor.
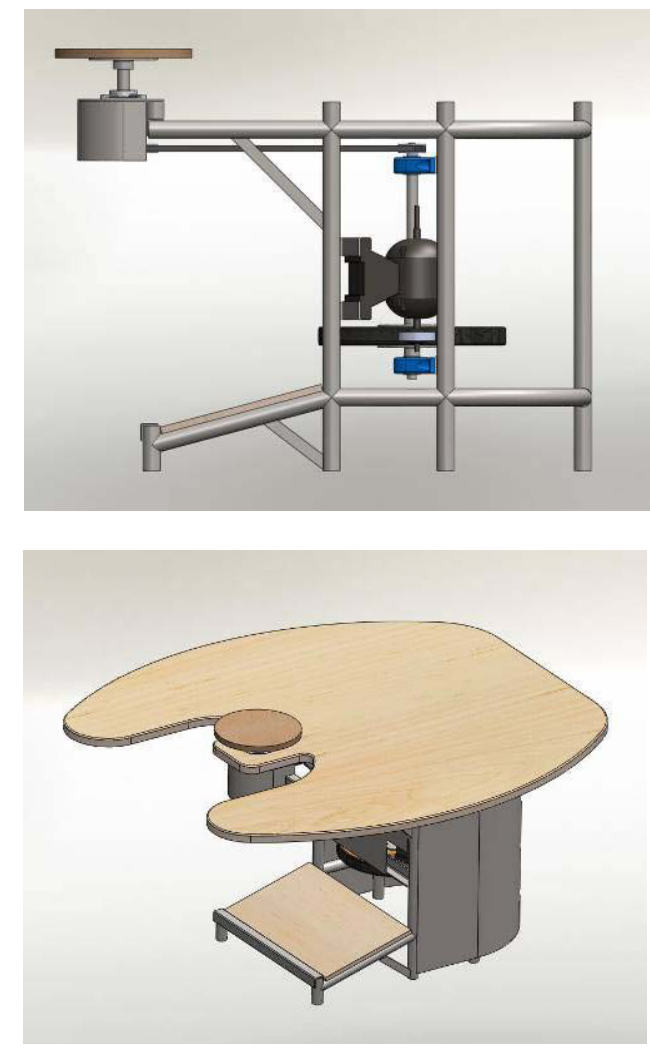

Fig. 7 - Model of the third design alternative, which already has the adjustments suggested by the group of craftsmen

A third piece of equipment deemed a prototype was made to test the new system proposed. It also prioritized using parts easily found in the local commercial market, an availability which will be helpful for future maintenance needs.

Tests conducted by using two pedals to drive the transmission system pedals demonstrated the efficiency of the system and won acceptance from the craftsmen. The next stage was one of technical refinement in partnership with the consulting team from TECRAL Ltda. 


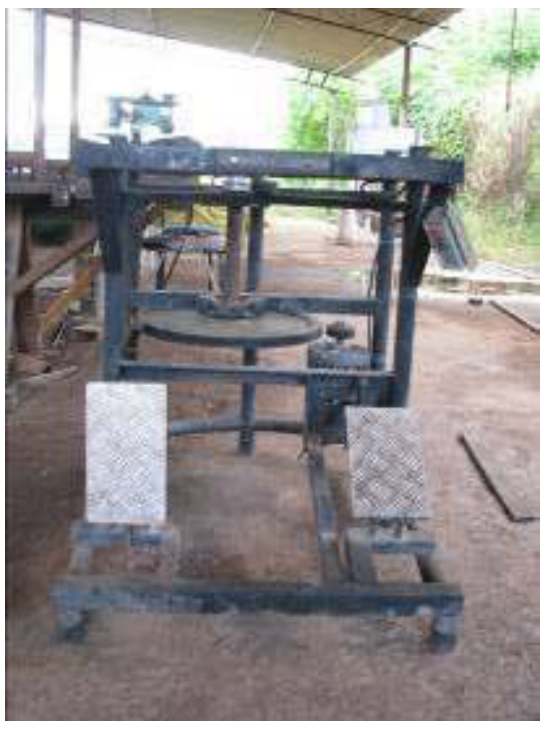

Fig. 8 - Model of the lathe with two pedals, at the finishing phase.

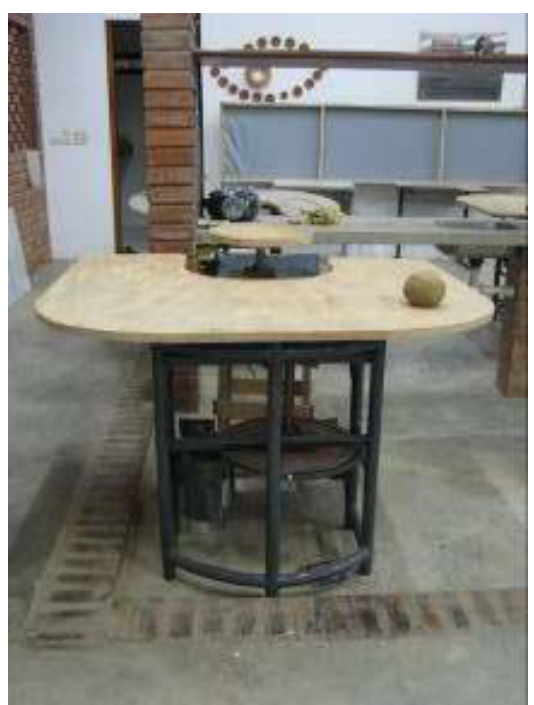

Fig. 9 - Model of the lathe with two pedals, tested by the craftsmen, and already set up in the Architect Wilson Queiroz Campos Júnior Crafts Center.

Having made the adjustments and these having been approved by the artisans, the lathe was tested for several months at Architect Wilson Campos Queiroz Júnior Crafts Center, and heavily used for the production of the group.

Some minor adjustments regarding vibration and the height of the turntable to make large pieces, over $0.70 \mathrm{~m}$ tall, were also performed. When the prototype was approved, 06 units of the potter's lathe were produced in the same mechanical workshop that the first model was fabricated in. Today, the lathes have been set up in the Center for the Craft Production of Ceramics, are used by the craftsmen and soon will be to support the running of pottery workshops for local young people.

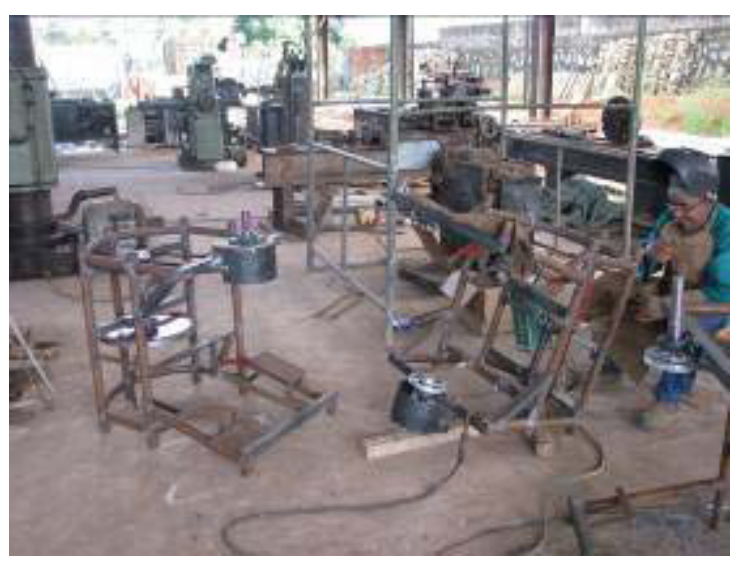

Fig. 10 - Production of the six potter's lathes

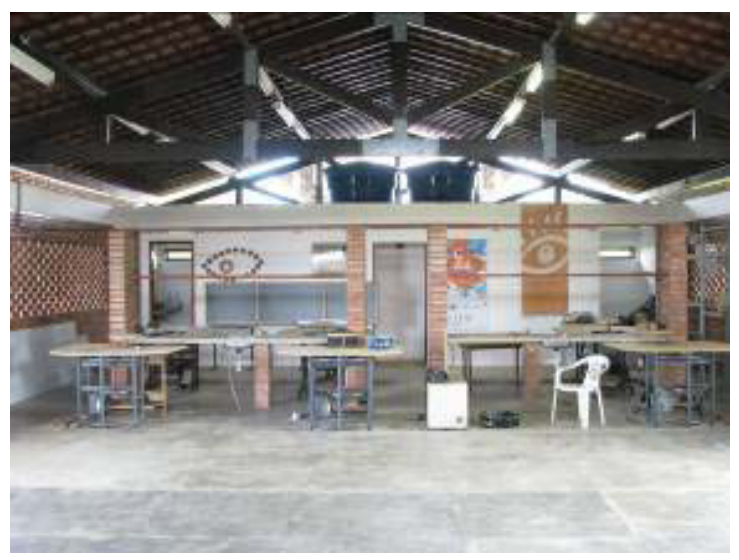

Fig. 11 - Lathes set up in the Architect Wilson Queiroz Campos Júnior Crafts Center. 


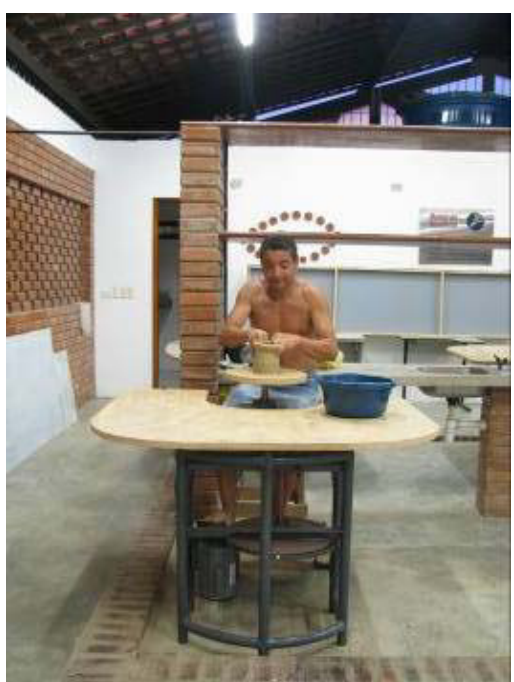

Fig. 12 - Craftsman using the potter's wheel in the Architect Wilson Queiroz Campos Júnior Crafts Center.

\section{Conclusions: design process + partnerships}

Regarding the design process, the need became evident to consider the technical and symbolic aspects as having equal importance, while the artifact was being developed. Winning the group of artisan's acceptance of the design by means of maintaining its original archetype and of incorporating the same mechanical principle of power transmission and controlling the speed of the community's lathes can be considered an example.

On the other hand, the design of the potter's lathe with ergonomic improvements in the biomechanical and dimensional aspects, characterizes the liaison needed between design and engineering, and the gains arising from this partnership. In the case of the lathe, there was no loss of productivity with the change in the behavior of modeling, and it was possible to reduce the risk of accidents and occupational diseases.

pretende a continuidade do fazer artesanal e a valorização da cultura do município.

Given the simplicity of the systems and their similarity to the traditional lathes, this project can be easily replicated for other communities of potters, scattered throughout the state of Pernambuco. This and other actions are part of the view of the Laboratory the Imaginary that in partnership with local authorities, this project seeks to foster continuity in craftsmanship and to add value to the culture of the municipality concerned.

\section{Bibliographical references}

[1] Silva, G.D.A., Cordeiro, E.J.D., Cavalcanti, V.P., Andrade, A. A. Q., Botelho, V. S. Tornos cerâmicos: melhorias ergonômicas no equipamento agregado valor a cultura local. In. www.oimaginario.com.br

[2] Grandjean, E., Kroemer, H. J. Manual de Ergonomia: adaptando o trabalho ao homem. 5 ed. Porto Alegre: Bookman, 2005.

[3] 10 cases do design brasileiro: os bastidores do processo de criação / coord. Auresnede Pires Stephan. V.2. Sao Paulo Ed. Blucher, 2010

[4] Andrade, A.; Cavalcanti, V. P.. Imaginário Pernambucano: design, cultura, inclusão social e desenvolvimento sustentável. Recife, 2006.

[5] Silva, A. C. R. ; Silva, G. D. A. ; Cavalcanti, Virginia Pereira ; Andrade, Ana Maria Queiroz de ; Cordeiro, E. J. D. . Desenvolvimento Tecnológico da Cerâmica Artesanal do Cabo de Santo Agostinho: um diálogo entre a tradição e inovação. In: 55 Congresso Brasileiro de Cerâmica, 2011, Ipojuca. 55 Congresso Brasileiro ed Cerâmica, 2011.

[6] Soares, M. M.. Design Participativo: uma experie ncia em Design Centrado no Usuário In: Anais do IV P\&D, Novo Hamburgo, RGS, 2000.

[7] Baxter, M. Projeto do Produto - Guia prático para o desenvolvimento de novos produtos. Ed. Egdard Blu cher. São Paulo, 1998. 